\title{
EVALUATION OF A TIME DEPENDENT AIR POLLUTION MODEL WITH A NEW VERTICAL TURBULENT PARAMETERIZATION
}

C. Mangia e U. Rizza, Institute ISIAtA of C.N.R.

Via Arnesano, Lecce, Italy

T. Tirabassi

Institute ISAO of C.N.R.

Via Gobetti 101, Bologna, Italy

G.A. Degrazia

Departamento de Física - CCNE

UFSM - Santa Maria,RS - Brazil

\begin{abstract}
The paper presents the evaluation of a model, with a new vertical eddy exchange parameterization, based on a general technique for solving the K-equation, using the truncated Gram-Charlier expansion (type A) of the concentration field and a finite set equations for the corresponding moments. The model can be applied routinely using as input simple ground-level meteorological data acquired by an automatic network. A performance evaluation is shown in the case of continuous emission from an elevated source in a variable boundary layer.
\end{abstract}

Rev. Ciência e Natura, Dispersion Process: $127 \quad-\quad 140 \quad, 2000$. 


\section{INTRODUCTION}

A distorting effect of the variation with height on the mean wind, both in speed and direction, is often observed in the development of puffs or plume smoke. This effect is most prominent in stable stratified conditions. In fact, windshear creates a variance in the wind direction, while vertical diffusion destroys this variance and tries to re-establish a non-skewed distribution. The interaction between vertical mixing and velocity shear is continuously effective.

In order to take into account the above phenomenon, we developed a time dependent model for the dispersion of passive material in the atmosphere (Tirabassi and Rizza, 1997). The model is based on a general technique for solving the K-equation using the truncated Gram-Charlier expansion of the concentration field and the finite set of equations for the corresponding moments. Actually, the Gram-Charlier expansion of type $A$ is a classical method for approximating a given distribution with moments of any order, basically consisting of a truncated expansion in terms of Hermite functions, whose coefficients are chosen so as to reproduce the sequence of moments of the distribution up to a given order (Kendall and Stuart, 1977). In particular, the model is well suited to applications where interest is focused mainly on certain overall properties of the horizontal patterns, rather than on specific values at particular point receptors.

The model can be applied routinely using as input simple ground-level meteorological data acquired by an automatic network.

\section{THE MODEL}

The advection diffusion equation describing the time evolution of concentration $\mathrm{C}$, due to a release at time $\mathrm{t}=0$ of a quantity $\mathrm{Q}$ of passive 
material by an elevated source placed at $(0,0,1)$, in a horizontally homogeneous atmospheric boundary layer is:

$$
\begin{aligned}
& \frac{\partial \mathrm{C}}{\partial \mathrm{t}}+\mathrm{u} \frac{\partial \mathrm{C}}{\partial \mathrm{x}}+\mathrm{dv} \frac{\partial \mathrm{C}}{\partial \mathrm{y}}=\frac{\partial}{\partial \mathrm{z}} \mathrm{K}_{\mathrm{z}} \frac{\partial}{\partial \mathrm{z}} \mathrm{C}+\mathrm{K}_{\mathrm{h}}\left(\frac{1}{\mathrm{~d}^{2}} \frac{\partial^{2} \mathrm{C}}{\partial \mathrm{x}^{2}}+\frac{\partial^{2} \mathrm{C}}{\partial \mathrm{y}^{2}}\right)+ \\
& \delta(\mathrm{t}) \delta(\mathrm{x}) \delta(\mathrm{y}) \delta(\mathrm{z}-1)
\end{aligned}
$$

where $\mathrm{x}$ is the along-wind co-ordinate, $\mathrm{y}$ the crosswind one and $\mathrm{z}$ the height; $\delta$ means delta function, $(\mathrm{u}, \mathrm{v}, 0)$ is the wind velocity vector, $\mathrm{K}_{\mathrm{z}}$ and $\mathrm{K}_{\mathrm{h}}$ are the eddy diffusivities for vertical and horizontal turbulent transport, respectively. All variables are non-dimensional, the corresponding scale factors being given by $\mathrm{H}_{\mathrm{s}}^{2} / \mathrm{K}_{\mathrm{s}}$ for time, $\mathrm{U}_{\mathrm{s}} \mathrm{H}_{\mathrm{s}}^{2} / \mathrm{K}_{\mathrm{s}}=\mathrm{d} \cdot \mathrm{H}_{\mathrm{s}}$ for a distance along the $\mathrm{x}$-axis, $\mathrm{H}_{\mathrm{s}}$ for the height and distance along the $\mathrm{y}$-axis, $\mathrm{K}_{\mathrm{s}}$ for diffusivities, $u_{s}$ for wind speed and $\mathrm{Q}_{0} /\left(\mathrm{d} \cdot \mathrm{H}_{\mathrm{s}}^{3}\right)$ for concentration. $\mathrm{K}_{\mathrm{s}}$ and $\mathrm{u}_{\mathrm{s}}$ represent the values of the dimensional $\mathrm{u}$ and $\mathrm{K}$ profiles at the dimensional source $\mathrm{H}_{\mathrm{s}}$.

The initial condition is:

$\lim _{t \rightarrow 0^{+}} C(x, y, z, t)=0$

and the no-flux boundary conditions applied at the ground level and at the mixing layer height $\left(\mathrm{H}_{m x}\right)$ are:

$\mathrm{K}_{\mathrm{Z}} \frac{\partial \mathrm{C}}{\partial \mathrm{z}}=0 \quad$ for $\mathrm{z}=0$ and $\mathrm{z}=\mathrm{H}_{m x}$

Since $C$ is exponentially small at asymptotic distances from the source on any horizontal plane, we can introduce the moments of its (x,y)-distribution:

$$
C_{m, n}=\iint_{-\infty}^{\infty} \mathrm{x}^{\mathrm{m}} \mathrm{y}^{\mathrm{n}} \cdot \mathrm{C} \cdot d x \cdot d y
$$

where $\mathrm{m}, \mathrm{n}$ are non-negative integers. 
Of course, $C_{m, n}$ are functions of height and of time. Their time evolution is governed by the double sequence of 1-dimensional diffusion equations, equivalent to the single three-dimensional (1):

$$
\begin{aligned}
& \frac{\partial C_{0,0}}{\partial \mathrm{t}}=D C_{0,0}+\delta(t) \delta(z-1) \\
& \frac{\partial C_{m, n}}{\partial \mathrm{t}}=D C_{m, n}+m u C_{m-1, n}+\mathrm{ndvC}_{\mathrm{m}, \mathrm{n}-1}+\mathrm{K}_{\mathrm{h}}\left(1 / d^{2} m(m-1) C_{m-2, n}+n(n-1) C_{m, n-2}\right)
\end{aligned}
$$

for $m+n \neq 0$ and $D$ the differential operator $(\partial / \partial \mathbf{z}) K_{z}(\partial / \partial \mathbf{z})$.

The initial condition is therefore written

$$
\lim _{t \rightarrow 0^{+}} C_{m, n}=0
$$

and the boundary conditions becomes

$$
K_{z} \frac{\partial \mathrm{C}_{\mathrm{m}, \mathrm{n}}}{\partial \mathrm{z}}=0 \quad \text { at } \mathrm{z}=0, \mathrm{H}_{m x}
$$

A classic method for approximating a given distribution with moments of any order is the Gram-Chalier expansion of type A, which is basically constituted by a truncated expansion in terms of Hermite functions, whose coefficients are chosen so as to reproduce the sequence of moments of the function up to a given order (Kendall and Stuart, 1977).

In the case of one-variate function of the concentration $\mathrm{C}(\mathrm{x})$, truncated to the fourth order, if $S_{k}$ is the skewness and $K_{u}$ is the Kurtosis, we have (Lupini and Tirabassi, 1983):

$$
C \cong C_{0} \frac{\mathrm{e}^{-\xi^{2} / 2}}{\sigma \sqrt{2 \pi}}\left[1+\left(\frac{K_{u}-3}{24}\right)\left(\xi^{4}-6 \xi^{2}+3\right)+\frac{S_{k}}{6} \xi\left(\xi^{2}-3\right)\right]
$$

where:

130 Rev. Ciência e Natura, Dispersion Process: $127 \quad-140 \quad, 2000$. 


$$
\begin{aligned}
& \xi=\frac{x-b}{\sigma} \\
& b=\frac{C_{1}}{C_{0}} \\
& \sigma^{2}=\frac{C_{2}}{C_{0}}-b^{2} \\
& S_{k}=\frac{1}{\sigma^{3}}\left[\frac{C_{3}}{C_{0}}-3 b \sigma^{2}-b^{3}\right] \\
& K_{u}=\frac{1}{\sigma^{4}}\left[\frac{C_{4}}{C_{0}}-6 b^{2} \sigma^{2}-4 b \sigma^{3} S_{k}-b^{4}\right]
\end{aligned}
$$

\section{BOUNDARY LAYER PARAMETERIZATION FOR UNSTABLE CONDITIONS}

In order to evaluate the diffusion coefficients in Eq. (3), utilising as input simple ground-level meteorological data acquired by an automatic network, we check two eddy exchange profiles $\left(\mathrm{K}_{z}\right)$ proposed by Degrazia et al. (1997) for an unstable boundary layer. The first one is:

$$
\frac{K_{z}}{w_{*} H_{m x}}=0.15 \Psi^{1 / 3}\left[1-\exp \left(-4 z / H_{m x}\right)-0.0003 \exp \left(8 z / z_{i}\right)\right]^{4 / 3}
$$

where the dissipation function is given by (Hojstrup, 1982):

$$
\Psi^{1 / 3}=\left[\left(1-\frac{z}{H_{m x}}\right)^{2}\left(-\frac{z}{L}\right)^{-2 / 3}+0.75\right]^{1 / 2}
$$


and $\mathbf{W}_{*}$ is the convective velocity scale, $\mathrm{H}_{m x}$ the boundary layer height, $\mathrm{L}$ the Monin-Obukhov length.

The second one can be written as:

$\frac{K_{z}}{w_{*} H_{m x}}=0.22\left(\frac{z}{H_{m x}}\right)^{1 / 3}\left(1-\frac{z}{H_{m x}}\right)^{1 / 3}\left[1-\exp \left(-4 \frac{z}{H_{m x}}\right)-0.0003 \exp \left(\frac{8 z}{H_{m x}}\right)\right]$

The eddy exchange profile (5) and (6) are based on spectral properties and the Taylor statistical diffusion theory (Degrazia et al., 1997).

\section{VALIDATION AGAINST COPENHAGEN DATA SET}

We evaluated the performance of the model with the two boundary layer parameterizations proposed, using the Copenhagen data set (Gryning and Lyck ,1984). The Copenhagen data set is composed of tracer $\mathrm{SF}_{6}$ data from dispersion experiments carried out in northern Copenhagen. The tracer was released without buoyancy from a tower at a height of $115 \mathrm{~m}$ and was collected at ground-level positions in up to three crosswind arcs of tracer sampling units. The sampling units were positioned 2-6 Km far from the point of release. We used the values of the crosswind-integrated concentrations $\left(\mathrm{C}_{\mathrm{y}}\right)$ normalised with the tracer release rate from Gryning et al. (1987). Tracer releases typically started up 1 hour before the tracer sampling and stopped at the end of the sampling period. The site was mainly residential with a roughness length of $0.6 \mathrm{~m}$. Generally, the distributed data set (Olesen, 1995) contains hourly mean values of concentrations and meteorological data. However, in this model validation, we used data with a greater time resolution kindly made available to us by Gryning. In particular,

132 Rev. Ciência e Natura, Dispersion Process: $127 \quad-140 \quad, 2000$. 
we used 20 minute averaged measured concentrations and 10 minute averaged values for meteorological data.

Tables 1, 2 and 3 report boundary layer height (only one value for each run), the friction velocity, and the Monin-Obukhov length, respectively, used in the simulations.

\begin{tabular}{lrccccccc}
\hline RUN & 2 & 3 & 1 & 4 & 5 & 7 & 8 & 9 \\
$\mathrm{H}_{m x}(\mathrm{~m})$ & 1920 & 1120 & 1980 & 390 & 820 & 185 & 810 & 2090
\end{tabular}

Table 1. Boundary layer height for the different runs.

\begin{tabular}{lllllllll}
\hline RUN & 1 & 2 & 3 & 4 & 5 & 7 & 8 & 9
\end{tabular}

TIME STEP

\begin{tabular}{lllllllll}
\hline 1 & .36 & .68 & .46 & .56 & .58 & .48 & .65 & .72 \\
2 & .37 & .67 & .45 & .51 & .52 & .48 & .79 & .73 \\
3 & .40 & .81 & .47 & .37 & .51 & .57 & .67 & .60 \\
4 & .43 & .68 & .39 & .44 & .58 & .62 & .67 & .59 \\
5 & .35 & .75 & .39 & .48 & .59 & .53 & .68 & .65 \\
6 & .34 & .74 & .40 & .48 & .52 & .65 & .65 & .71 \\
7 & .42 & .76 & .40 & .39 & .52 & .63 & .68 & .73 \\
8 & .43 & .82 & .41 & .40 & .45 & .65 & .67 & .73 \\
9 & .40 & .76 & .31 & .39 & .44 & .66 & .73 & .73 \\
10 & .37 & .73 & .34 & .39 & .44 & .62 & .73 & .66 \\
11 & .35 & .69 & .39 & .39 & .44 & .52 & .75 & .67 \\
12 & .36 & .66 & .40 & .39 & .43 & .62 & .69 & .74 \\
\hline
\end{tabular}

Table 2. Friction velocity $(\mathrm{m} / \mathrm{s})$ for the different runs and time steps. Every time step corresponds at 10 minute.

Rev. Ciência e Natura, Dispersion Process: $127 \quad-140 \quad, 2000$. 


\begin{tabular}{|c|c|c|c|c|c|c|c|c|}
\hline $\begin{array}{l}\text { RUN } \\
\text { TIME STEP }\end{array}$ & 1 & 2 & 3 & 4 & 5 & 7 & 8 & 9 \\
\hline 1 & $\begin{array}{c}-2 \\
6\end{array}$ & -178 & -152 & -75 & -492 & -71 & -71 & -793 \\
\hline 2 & $\begin{array}{l}-2 \\
3\end{array}$ & -227 & -194 & -42 & -215 & -80 & -85 & -471 \\
\hline 3 & $\begin{array}{l}-8 \\
3\end{array}$ & -311 & -106 & -23 & -368 & -64 & -47 & -202 \\
\hline 4 & $\begin{array}{l}-4 \\
2\end{array}$ & -160 & -101 & -32 & -735 & -111 & -49 & -366 \\
\hline 5 & $\begin{array}{l}-3 \\
6\end{array}$ & -203 & -129 & -71 & -366 & -177 & -45 & -633 \\
\hline 6 & $\begin{array}{l}-4 \\
2\end{array}$ & -286 & -70 & -80 & -273 & -67 & -63 & -13588 \\
\hline 7 & $\begin{array}{l}-4 \\
7\end{array}$ & -155 & -83 & -83 & -273 & -87 & -41 & -593 \\
\hline 8 & $\begin{array}{c}-3 \\
8\end{array}$ & -228 & -60 & -101 & -262 & -71 & -47 & -471 \\
\hline 9 & $\begin{array}{l}-8 \\
3\end{array}$ & -184 & -106 & -129 & -395 & -56 & -70 & -389 \\
\hline 10 & $\begin{array}{c}-2 \\
1\end{array}$ & -389 & -42 & -129 & -395 & -111 & -64 & -375 \\
\hline 11 & $\begin{array}{l}-3 \\
2\end{array}$ & -133 & -101 & -129 & -395 & -215 & -52 & -262 \\
\hline 12 & $\begin{array}{l}-2 \\
9\end{array}$ & -375 & -70 & -129 & -759 & -123 & -39 & -252 \\
\hline
\end{tabular}

Table 3. Monin-Obukhov length $(\mathrm{m})$ for the different runs and time steps. Every time step corresponds at 10 minute.

In Figure 1 the comparison of the two vertical eddy profiles (5) and (6) for 4 runs are reported.

Each profile it is obtained with 1-hour average meteorological data (steps 7-12)

134 Rev. Ciência e Natura, Dispersion Process: $127 \quad-140 \quad, 2000$. 


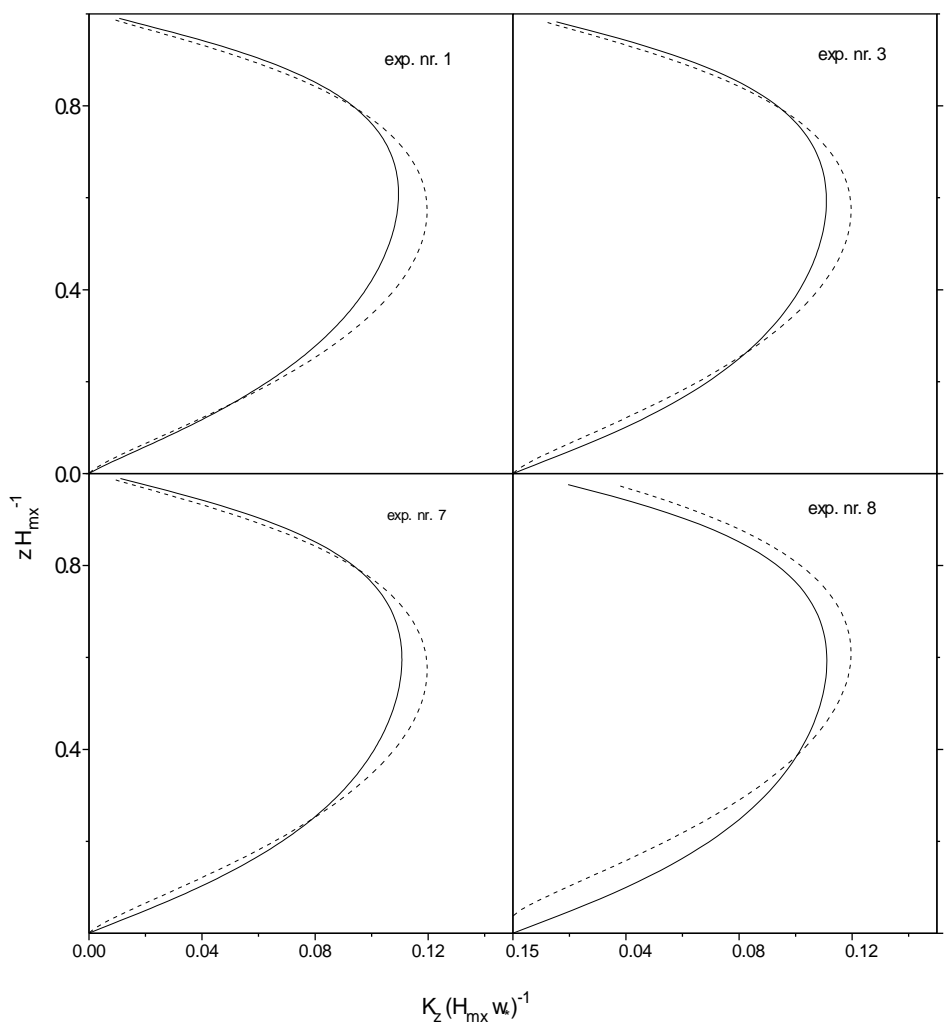

Fig. 1. Nondimensional vertical eddy diffusivity profile according to equation (5) (continuos line) and equation (6) (dashed line)

Figure 2 and 3 show the cross-wind integrated concentrations normalized with emission at ground-level predicted by the model against the

Rev. Ciência e Natura, Dispersion Process: $127 \quad-140 \quad, 2000$. 
observed values of the Copenhagen data set, for the eddy exchange profile (5) and (6), respectively.

Moreover, Table 4 presents some statistical indices, defined as normalised mean square error (nmse), correlation coefficient ( $r$ ), factor of two (fa2), fractional bias (fb) and fractional standard deviation (fs):

nmse $=\frac{\overline{\left(C_{o}-C_{p}\right)^{2}}}{\overline{C_{o}} \overline{C_{p}}}$

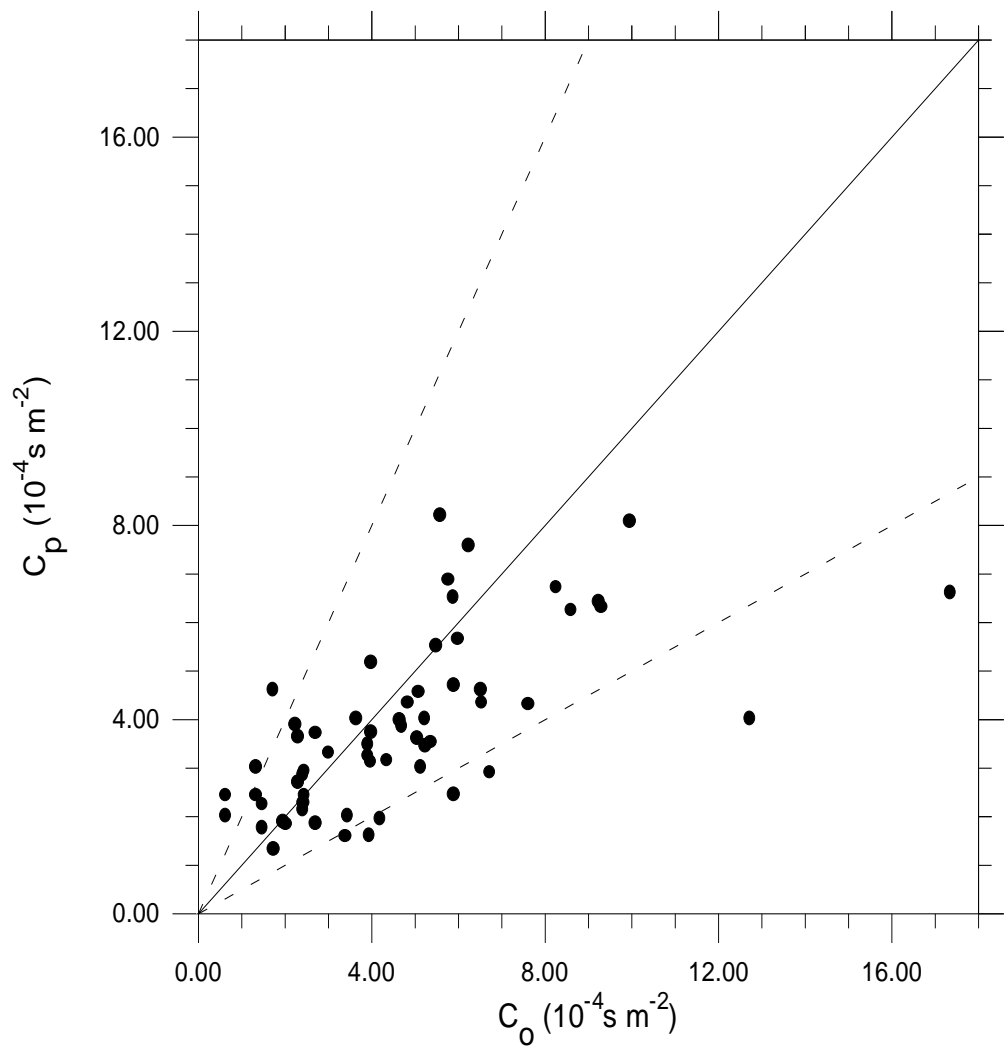

Fig. 2. Scatter plot of observed $\left(C_{0}\right)$ versus predicted $\left(C_{p}\right)$ crosswind-integrated concentrations normalized with the emission source rate in the case of eddy exchange profile (5). Points between dashed lines are in a factor of two.

136 Rev. Ciência e Natura, Dispersion Process: $127 \quad-140 \quad, 2000$. 
$r=\frac{\overline{\left(C_{o}-\overline{C_{o}}\right)\left(C_{p}-\overline{C_{p}}\right)}}{\sigma_{o} \sigma_{p}}$

fa2 = data for which $0.5 \leq C_{p} / C_{o} \leq 2$

$\mathrm{b}=2 \frac{\overline{C_{o}}-\overline{C_{p}}}{\overline{C_{o}}+\overline{C_{p}}}$

fs $=2 \frac{\sigma_{o}-\sigma_{p}}{\sigma_{o}+\sigma_{p}}$

where the subscript "o" and "p" are for the observed and predicted concentrations, respectively, while $\sigma$ is the standard deviation.

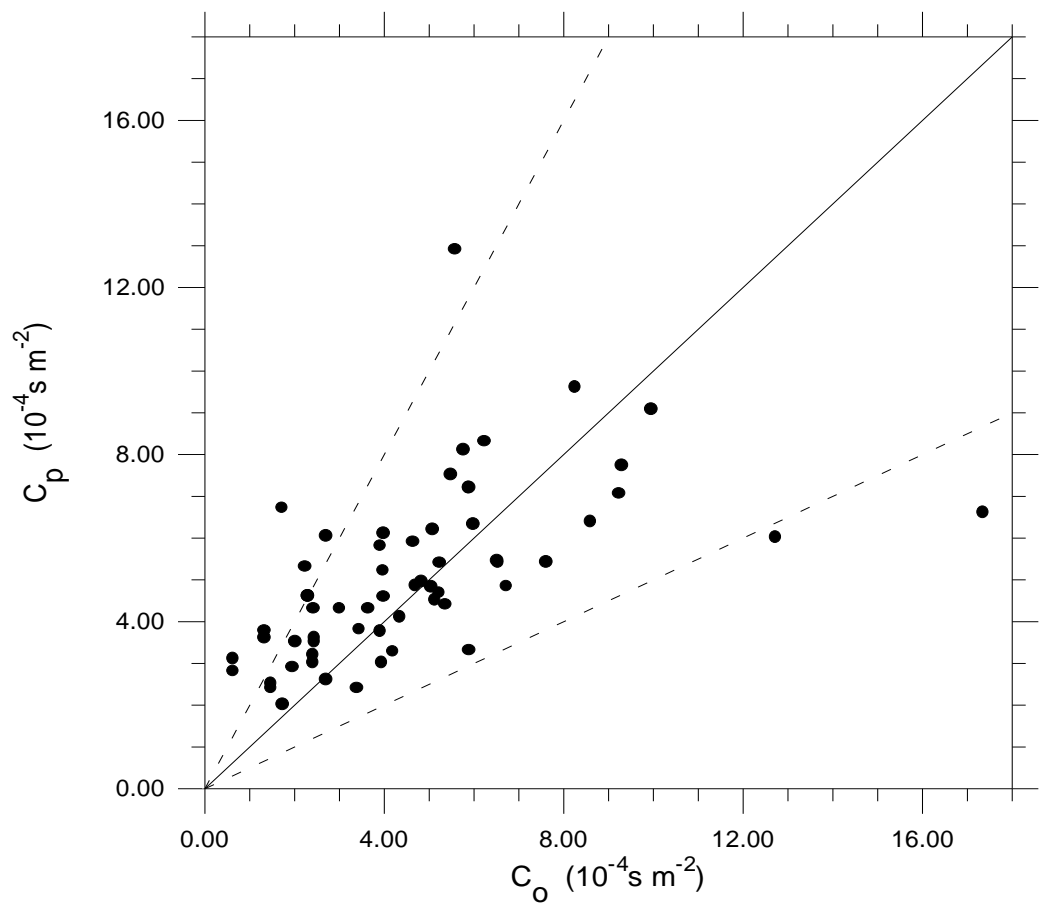

Fig. 3. Scatter plot of observed $\left(C_{o}\right)$ versus predicted $\left(C_{p}\right)$ crosswind-integrated concentrations normalized with the emission source rate in the case of eddy exchange profile (6). Points between dashed lines are in a factor of two.

Rev. Ciência e Natura, Dispersion Process: 127 - 140 , 2000. 


\begin{tabular}{lccccc}
\hline & Nmse & $\mathrm{R}$ & fa2 & fb & fs \\
\hline $\mathrm{K}_{z}$ profile (5) & 0.32 & 0.66 & 0.82 & 0.20 & 0.53 \\
$\mathrm{~K}_{z}$ profile (6) & 0.26 & 0.57 & 0.83 & -0.084 & 0.38 \\
\hline
\end{tabular}

Table 4. Statistical evaluation of model results

\section{CONCLUSIONS}

We have presented a time dependent air pollution model based on a general technique for solving the K-equation, using the truncated Gram-Charlier expansion (type A) of the concentration field and a finite set equations for the corresponding moments.

The model can be applied routinely using as input simple ground-level meteorological data acquired by an automatic network. In fact, the model needs diffusion parameterizations based on fundamental parameters to describe the characteristics of the atmospheric boundary layer that can be evaluated by ground measurements Holtslag and Van Ulden (1983, Weil and Brower (1984), Van Ulden and Holtslag (1985), Trombetti et al. (1986), Degrazia et al., (1997)

The model utilises a new turbulent prameterization based on spectral properties and Taylor statistical diffusion theory.

The crosswind-integrated concentrations calculated with the model were compared with the tracer data of the Copenhagen data set. Generally, the distributed data set (Olesen, 1995) contains hourly mean values of concentrations and meteorological data. However, in this model validation, we used data with a greater time resolution kindly made available 
to us by Gryning. In particular, we used 20 minute average concentrations of $\mathrm{SF}_{6}$ and 10 minute average values for meteorological data.

On analysing the results and relative statistic, we can see that the dispersion model reproduces adequately the experimental measurements with the parameteriztion utilised. It does not appear any significante difference between the two parameterizations used.

\section{REFERENCES}

Degrazia G.A., Rizza U., Mangia C. and Tirabassi T. Validation of a new turbulent parameterization for dispersion models in convective conditions. Bound. Layer Meteor., 85, pp. 243-254, 1997.

Gryning S.E. and E. Lyck. Atmospheric dispersion from elevated sources in an urban area: comparison between tracer experiments and model calculations. J. Clim. Appl. Meteor., 23, 651-660, 1984.

Gryning S.E., Holtslag A.A.M., Irwin J.S. and Siversten B, Applied dispersion modelling based on meteorological scaling parameters. Atmos. Environ., 21, pp. 79-89, 1987.

Hojstrup J., Velocity spectra in the unstable boundary layer. J. Atmos. Sci., 39, pp. 2239-2248, 1982.

Holtslag A.A.M. and van Ulden A.P., 1983. A simple scheme for daytime estimation of surface fluxes from routine weather data. J. Clim. Appl. Meteor., 22, 517-529. 
Kendall M. and Stuart A., The Advanced Theory of Statistic. Charles Griffin, London, I, pp. 472, 1997.

Lupini R. and Tirabassi T., Solution of the advection-diffusion equation by the moments method. Atmos. Environ., 17, pp. 965-971, 1983.

Olesen H.R. . Datasets and protocol for model validation. Int. J. Environment and Pollution, 1995, 5, pp. 693-701.

Tirabassi T. and Rizza U., Boundary layer parameterization for a non-Gaussian puff model. J. of appl.. Meteor., 36, pp. 1031-1037, 1997.

Trombetti F.,Tagliazucca M., Tampieri F. and Tirabassi T.. Evaluation of similarity scales in the stratified surface layer using wind speed and temperature gradient. Atmos. Environ., 20, 2465-2471, 1986.

Van Ulden A.P. and Holstlag A.A.M.. Estimation of atmospheric boundary layer parameters for diffusion applications. J. Clim. Appl. Meteor., 24, 1196-1207, 1985.

Weil J.C. and Brower R.P. An update gaussian plume model for tall stacks. APCA, 34, pp. 818-827, 1984.

140 Rev. Ciência e Natura, Dispersion Process: $127 \quad-140 \quad, 2000$. 